DOI: 10.12731/2077-1770-2018-2-4-60-69

УДК 008: 130.2

\title{
АНАЛИЗ ВЗАИМОСВЯЗИ \\ СОЦИАЛЬНО-ЭКОНОМИЧЕСКОГО САМОЧУВСТВИЯ \\ НАСЕЛЕНИЯ ХАКАСИИ И ИХ ОЦЕНОК ХАРАКТЕРА МЕЖЭТНИЧЕСКОГО ВЗАИМОДЕЙСТВИЯ В 1994-2016 ГГ.
}

Аксютин Ю.М.

В статье на основе анализа материалов социологических исследований (1994-2016 г2.) рассматриваются актуальные вопросы корреляции сочиально-экономического самочувствия населения Хакасии и их оценок характера межэтнического взаимодействия в республике.

Метод или методология проведения работы. Основу исследования образует консенсусный подход к интерпретащии содержсания соџиокультурных феноменов, компаративистскийметод анализа данных, метод формализованного интервьюирования жителей Хакасии (520 чел.).

Результаты. Автор констатирует, что порядка 40\% респондентов межнациональные отночения оченивают как стабильно напряженные. Пиковые значения негативных оценок межнациональных отношений приходятся на периоды экономической дестабилизации, а усиление межнациональной напряженности возникает как реакция на снижение уровня материального обеспечения жителей региона.

Результаты исследования могут быть применены в сфере образования, социально-политического прогнозирования.

Ключевые слова: постсоветский сочиум; Хакасия; межэтнические отношения; экономическая ситуация; кризис; конфликт.

\section{THE ANALYSIS OF CORRELATION SOCIO-ECONOMIC WELFARE OF KHAKASSIA INHABITANTS AND THEIR ASSESSMENTS OF INTERETHNIC RELATIONS DEPENDENCE 1994-2016}

Aksutin Yu.M.

Abstract. This article is based on sociological researches 1994-2016. It describes the following issues: first, interethnic relations in post-Soviet 
Khakassia inhabitants 'points of view and their characteristics; second, correlation between interethnic situation evaluation and the success in adaptation to social and economic situation. It is noticed that post-Soviet social and economic transformations influenced interethnic relations in Khakassia.

Methods or methodology of work conduct. The base of research is the consensus approach to socio-cultural phenomenon, comparative analysis and interview of people (Republic of Khakassia - 520 people).

The results. The results are in the fact: about $40 \%$ of respondents consider interethnic relations to be intense. The most negative evaluations of interethnic cooperations are traditionally due to crises and economical disasters.

The research results can be used in education, social and political prediction.

Keywords: post-Soviet society; Khakassia; interethnic relations; economic situation; crisis; conflict.

\section{Введение}

Произошедшие в России четверть века назад социально-политические трансформации имели своим следствием не только исчезновение Советского государства, но значительно осложнили экономическую ситуацию и межэтнические отношения в регионах страны. Обозначенная проблема не осталась за границами внимания исследователей. Более того, сложилась традиция конкуренции ряда теоретических подходов и моделей межэтнокультурного взаимодействия [9, с. 158]. В то же время исследования наличествующей ситуации в оценках и представлениях самих жителей регионов все еще весьма редки. Это особенно актуально для тех субъектов Российской Федерации, где взаимодействуют ежедневно и непосредственно представители разных этносов. Одним их таких субъектов является Республика Хакасия, в которой проживают представители порядка ста этнических групп. Анализ взаимосвязи между социально-экономическим самочувствием населения Хакасии и их оценками характера межэтнического взаимодействия составляет предмет нашего исследования. 


\section{Материалы и методы исследования}

С целью анализа взаимосвязи оценок жителями Хакасии характера межэтнических отношений и социально-экономическим самочувствиемв постсоветский период привлекались результаты вторичного анализа сопоставимых материалов (вопросы анкет сформулированы по единому образцу), проводимых в Хакасии массовых опросов 1994-2016 гг. [2, 3, 4, 5, 6, 7, 8, 10]. В качестве основного метода сбора первичных данных применялось формализованное анкетирование.

\section{Результаты исследования}

В процессе построения динамической модели социально-экономическогосамочувствия на основе оценок жителей республики было установлено, что степень материальной обеспеченности респондентов в 1996-2005 гг, если исходить из покупательной способности их доходов выглядела следующим образом. Доля лиц, «ни в чем себе не отказывающих», снизилась до критических значений $3,7 \%$ в 1994 г. 12\% в 1996 г. и 1\% в 2005 г. По мнению экспертов [10, с. 17-18] это связано с экономическими кризисами 1991 г. и особенно 1998 г., которые привели к депрессии несырьевого региона и пополнению «второй» («денег хватает на продукты и одежду» отметили в 1994 г. - 30\%; в 1996 г. - 42\%; 2005 г. - 42\%) и «третьей» группы («на продукты денег хватает, но покупка одежды вызывает финансовые затруднения» отметили в 1994 г. - 40\%; в 1996 г. $25 \%$; в 2005 г. - 45\%). Изменения в четвертой группе «неимущих» («денег не хватает даже на продукты») имели стабильную положительную динамику, к этой категории отнесли себя в 1994 г. - 26\%; в 1996 г. - 12\%; в 2005 г. - 12\% респондентов. В таком контексте интерес представляет анализ взаимосвязи между социально-экономическим самочувствием жителей Хакасии и их оценками межэтнических отношений в республике.

Проводимые в 1990-2000-е гг. в Хакасии исследования выявили, что порядка 50\% опрошенных характеризуют межнациональные отношения в республике как стабильные (1994 г. - 43\%; 1996 г. - 
69\%). Напротив, 35\% опрошенных в 1994 г. и 21\% в 1996 г. отметили наличие напряженности. Сильную напряженностьотмечали порядка 3-5\%. В 2005 г. уже большинство опрошенных (74\%) считали межэтнические отношения в республике благоприятными, $18 \%$ ощущали напряженность, 3\% чувствовали сильную напряженность. В качестве основных причин напряженности (можно было выбрать 3 варианта ответов) сами респонденты называли: ухудшение экономической ситуации (44\%), миграцию (25\%), бытовой национализм (13\%), политическую нестабильность (13\%). Анализ результатов проводимых в обозначенный период опросов позволяет сделать вывод, что социально-экономическое самоощущение жителей республики и кризисные процессы в экономике оказывали определенное воздействие на оценки напряженности межэтнических отношений. Социальный кризис и снижение материальной обеспеченности «поднимает на поверхность» старые обиды, негативные стереотипы межэтнического общения. Дестабилизация межэтнических отношений связана, помимо прочего, с трансформацией интернационалистской ментальности «советского человека», девальвацией советской идеологии с ее принципами дружбы и сотрудничества между народами, усилением миграции из Китая и бывших советских республик.

Проведенные нами в 2011-2016 гг. опросы фиксировали изменение ситуации в плане социально-экономического самоощущения жителей республики и оценок ими характера межэтнических отношений. В частности, стабильно возрастал процент относящих себя к «первой» группе, имеющих возможность приобретать вещи длительного пользования и достаточно дорогостоящие вещи (2011 г. - 27,8\%; 2014 г. - 28,1\%; 2015 г. - 26,4\%; 2016 г. - 33,6\%), за исключением послекризисного 2015 г. Серьезные подвижки наблюдались во «второй» группе, т.е. численность людей, которым хватает средств на продукты и на одежду (2011 г. - 39,5\%; 2014 г. - 49\%; 2015 г. - 46,4\%; 2016 г. $43,5 \%$ ), возрастала до кризисного 2014 г. и поступательно снижалась к 2016 г. до значений начала 2000-х гг. Фиксировалась устойчивая положительная тенденция к снижению процента малообеспеченных (2011 г. $-22,5 \% ; 2014$ г. $-20,6 \% ; 2015$ г. $-21,5 \% ; 2016$ г. $-18,8 \%)$ и не- 
обеспеченных (2011 г. - 8,3\%; 2014 г. - 2,1\%; 2015 г. - 7,5\%; 2016 г. $4 \%$ ). Анализ результатов опросов дает основание утверждать, что стабильный рост числа высоко- и среднеобеспеченных - явление скорее кажущееся, характеризующееся значительными внутригрупповыми переходами и чувствительностью к изменениям в экономике (это рельефно проявилиопросы 2014-2015 гг.).

Социально-экономические и политические процессы второй половины 2000-х гг. также оказывали на оценки респондентов характера межэтнического взаимодействия негативное воздействие, которое фиксировали результаты опроса 2011 г. Порядка 42,5\% опрошенных отметили тогда, что межнациональные отношения в республике благоприятны, 41,5\% ощущали напряженность и 4,5\% отметили сильную напряженность. Межэтнические отношения в республике в 2013 г. описывались по-прежнему в терминах «стабильной напряженности». Благоприятными их сочли $-53,3 \%$ респондентов. Скрытую напряженность ощущали 36,5\%, наличие сильной напряженности отметили 4,4\% опрошенных. Однако экономически сложный период 2014-2015 гг. отметился повышением тревожности республиканского социума. До 37\% в 2014 г. снизилась доля опрошенных, считающих межнациональные отношения в регионе благоприятными. Скрытую напряженность ощущали $35,2 \%$, а сильную - 18,5\% респондентов. Результаты опроса 2015 г. подтвердили прогноз посткризисного смягчения оценок характера межнациональных отношений. Более половины респондентов $(54,6 \%)$ сочли межнациональные отношения в республике благоприятными. Наличие скрытой напряженности отметили $34,2 \%$ опрошенных, а сильную напряженность - 3,7\% (против 18,5\% в 2014 г.). Данные опроса 2016 г. подтвердили вывод о стабилизации характера межэтнических отношений в значениях предыдущего года. Процент респондентов, считающих межнациональные отношения благоприятными, продолжил снижение до 48,8\%, напряженность ощущали $36,9 \%$, а сильную напряженность $-3,8 \%$ опрошенных. В массовом сознании основными факторами эскалации напряженности выступали: бытовой национализм (31\%), миграция 
(28,9\%), ухудшение экономической ситуации (19\%), политическая нестабильность (14,6\%).Отмечаемые населением республики факты усиления бытового национализма имеют свою экономическую обусловленность (поиск «виновных», «чужих» и т.п.). Негативное восприятие миграции во многом характеризуется тем, что в мигрантах усматривается угроза усиления экономической конкуренции, вытеснения местного населения из ранее занятых экономических ниш (сезонные заработки, сельское хозяйство и др.).

\section{Обсуждение}

Проблема межнациональных отношений как важная составляющая этносоциальных процессов существует практически во всех регионах России [11, с. 130-138]. Признавая комплексность состава факторов межнациональной напряженности, исследователи по-разному расставляли их в своих авторских иерархиях. Одни эксперты акцентировали внимание на процессах трансформации ценностей и идентичностей россиян $[1$, с. 99]. В концепциях других исследователей приоритет отдавался социально-экономическим и миграционным процессам [10, с. 26; 11, с. 197]. Результаты проведенных в регионе опросов свидетельствуют в пользу той гипотезы, что социально-экономическое самоощущение населения в регионах постсоветской России выступает одним из ведущих факторов, определяющих все важнейшие представления и оценки респондентов, в том числе в сфере межнациональных отношений.

\section{Заключение}

Проведенное в регионе исследование подтвердило, что социальные и политические трансформации двух последних десятилетий оказали значительное воздействие на самосознание жителей Хакасии. Во-первых, межнациональные отношения, по результатам проводившихся с середины 1990-х гг. опросов, жителями республики характеризуются как напряженные (порядка 35-40\%). Во-вторых, наличие и стабильность напряженности определяются целым комплексом факторов, среди которых наиболее выражено влияние эко- 
номических процессов в республике и стране в целом. Результаты исследования убедительно свидетельствуют, что усиление межнациональной напряженности часто выступает реакцией на снижение уровня материального обеспечения жителей региона, усиление миграционного нажима и политическую дестабилизацию.

Информация о конфликте интересов. Автор заявляет об отсутствии конфликта интересов.

Информация о спонсорстве. Исследование выполнено при финансовой поддержке РФФИ и Правительства Республики Хакасия в рамках научного проекта № 18-411-190002.

\section{Список литературы}

1. Аксютин Ю.М. Ценностные ориентации и этнокультурная комплементарность жителей Саяно-Алтая // Современные исследования социальных проблем. 2018. Т. 10. № 1-2. С. 99-106.

2. Жители Хакасии о своей жизни: результаты социологического исследования / Отв. ред. Л.В. Анжиганова, Г.Г. Котожеков. Абакан: Хакасское книжное издательство, 1994. 72 с.

3. Межнациональные отношения в Хакасии: результаты социологического исследования / Отв. ред. Л.В. Анжиганова, Г. Г. Котожеков. М.; Абакан: ХРИПКиПРО Роса, 1997. 51 с.

4. Социологическое исследование (2011 г.) по проекту: «Межнациональные отношения в Республике Хакасия в оценках и представлениях массового сознания населения». Выборочная совокупность в Хакасии - 500 чел.

5. Социологическое исследование (2013 г.) в рамках ФЦП по теме: «Надэтническая идентичность: анализ состояния и оценка потенциала оптимизации региональной модели межкультурного взаимодействия〉 (соглашение: 14.В37.21.0511). Выборочная совокупность в Хакасии - 520 чел.

6. Социологическое исследование (2014 г.) в рамах Гранта Президента РФ (МК-2456.2013.6). Выборочная совокупность в Хакасии 520 чел. 
7. Социологическое исследование (2015 г.) по проекту: «Трансформации надэтнической идентичности в контексте трендов традиционализации и модернизации: имперскость, советскость, этничность и российская гражданственность». Выборочная совокупность в Хакасии - 520 чел.

8. Социологическое исследование (2016 г.) в рамках Гранта Президента РФ (МК-6746.2015.6). Выборочная совокупность в Хакасии - 520 чел.

9. Чистанов М.Н., Чистанова С.С., Маслова Т., Кудряшов И.С. Проблема построения новых теоретических моделей межкультурного взаимодействия в контексте реализации проекта «Нового шелкового пути» // Вестник Новосибирского государственного педагогического университета. 2018. Т. 8. № 1. С. 158-172.

10.Этносоциальная ситуация в Республике Хакасия в оценках и представлениях массового сознания / Под ред. Л.В. Анжигановой. Абакан: ХГУ им. Н. Ф. Катанова, 2006. 96 с.

11. Этносоциальные процессы и этнонациональная политика в регионах Сибири / Под. ред. Ю.В. Попкова. Новосибирск: СОРАН, 2015. 273 с.

\section{References}

1. Aksutin Yu.M. Tsennostnye orientatsii i etnokul'turnaya komplementarnost' zhiteley Sayano-Altaya [Value orientation and ethnic and cultural complementarity of the inhabitants of the Sayan-Altai]. Sovremennye issledovaniya sotsial'nykh problem. no. 10. № 1-2. (2018): 99-106.

2. Zhiteli Khakasii o svoey zhizni: rezul 'taty sotsiologicheskogo issledovaniya [Residents of Khakassia about their lives: the results of sociological research] / Ed. L.V. Anzhiganova, G.G. Kotozhekov. Abakan: Khakasskoe knizhnoe izdatel'stvo, 1994. 72 p.

3. Mezhnatsional'nye otnosheniya v Khakasii: rezul'taty sotsiologicheskogo issledovaniya [Interethnic relations in the Republic of Khakassia: the results of sociological research] / Ed. L.V. Anzhiganova, G.G. Kotozhekov. M.; Abakan, 1997. 51 p.

4. Sotsiologicheskoe issledovanie (2011 g.) po proektu: «Mezhnatsional'nye otnosheniya $v$ Respublike Khakasiya $v$ otsenkakh i predstavleniyakh massovogo soznaniya naseleniya» [Sociological research: 
Interethnic relations in the Republic of Khakassia in the estimates and representations of the mass consciousness of the population].

5. Sotsiologicheskoe issledovanie (2013 g.) v ramkakh FTsP po teme: «Nadetnicheskaya identichnost': analiz sostoyaniya i otsenka potentsiala optimizatsii regional 'noy modeli mezhkul'turnogo vzaimodeystviya» (soglashenie: 14.B37.21.0511) [Sociological research: Supra-ethnic identity: analysis of the state and assessment of the optimization potential of the regional model of intercultural interaction].

6. Sotsiologicheskoe issledovanie (2014 g.) v ramakh Granta Prezidenta $R F$ [Sociological research in the framework of the Grant of the President of the Russian Federation].

7. Sotsiologicheskoe issledovanie (2015 g.) po proektu: "Transformatsii nadetnicheskoy identichnosti $v$ kontekste trendov traditsionalizatsii $i$ modernizatsii: imperskost', sovetskost', etnichnost' i rossiyskaya grazhdanstvennost'» [Sociological research: "Transformation of supra-ethnic identity in the context of trends of traditionalization and modernization: Imperial, Soviet, ethnic and Russian citizenship"].

8. Sotsiologicheskoe issledovanie (2016 g.) v ramkakh Granta Prezidenta $R F$ [Sociological research in the framework of the Grant of the President of the Russian Federation] (MK-6746.2015.6).

9. Chistanov M.N., Chistanova S.S., Maslova T., Kudryashov I.S. Problema postroeniya novykh teoreticheskikh modeley mezhkul'turnogo vzaimodeystviya v kontekste realizatsii proekta "Novogo shelkovogo puti" [The problem of building new theoretical models of intercultural interaction in the context of the project "New silk road"]. Vestnik Novosibirskogo gosudarstvennogo pedagogicheskogo universiteta, no. 1 (2018): 158-172.

10. Etnosotsial'naya situatsiya $v$ Respublike Khakasiya $v$ otsenkakh i predstavleniyakh massovogo soznaniya [Ethno-social situation in the Republic of Khakassia in the assessments and representations of mass consciousness]. Abakan: HGU N.F. Katanova., 2006. 96 p.

11. Etnosotsial'nye protsessy $i$ etnonatsional'naya politika $v$ regionakh Sibiri [Ethno-social processes and ethno-national policy in the regions of Siberia]. Novosibirsk: SO RAN, 2015. 273 p. 


\section{ДАННЫЕ ОБ АВТОРАХ}

Аксютин Юрий Михайлович, доцент кафедры философии и культурологии, кандидат философских наук, доцент Хакасский государственный университет им. Н.Ф. Катанова Проспект Ленина, 90, г. Абакан, 655017, Российская Федеращия aksutum@mail.ru

\section{DATA ABOUT THE AUTHORS}

Aksutin Yuri Mikhailovich, Lecturer of Philosophy and Culturology Chair, $\mathrm{PhD}$ in Philosophy, Docent Khakas State University named after N. F. Katanov 90, Lenin Str., Abakan, 655017, Russian Federation aksutum@mail.ru ORCID: 0000-0001-5996-3686 